\title{
5
}

\section{Investigation of the Potential to Use Real-Time Data in Production Planning and Control of Make to Order (MTO) Manufacturing Companies}

\author{
Manuel Woschank, Patrick Dallasega, \\ and Johannes A. Kapeller
}

\subsection{Introduction}

In an explorative research study Woschank et al. (2020) the authors stated that the usage of real-time data in logistics and operations management is an important principle of Industry 4.0. This becomes especially important because manufacturing processes are constantly generating a large volume of data in the fourth industrial revolution. Up to now, only a limited amount of data is used for production planning and control (PPC) strategies. Real-time-orientated PPC strategies enable highly responsive, reconfigurable, and time-efficient production systems

M. Woschank (凶) · J. A. Kapeller

Montanuniversitaet Leoben, Erzherzog-Johann-Strasse 3/1, 8700 Leoben, Austria

e-mail: manuel.woschank@unileoben.ac.at

P. Dallasega

Industrial Engineering and Automation (IEA), Faculty of Science and Technology, Free University of Bozen-Bolzano, Bolzano, Italy e-mail: patrick.dallasega@unibz.it 
(Arica and Powell 2014; Dallasega et al. 2019a; Dallasega et al. 2019b; Dallasega et al. 2020) based on the concept of mass customization (Bednar and Modrak 2014; Matt and Rauch 2016). Moreover, the integration of modern information and communication technology, interconnected networks, and physical processes is named Cyber-Physical Systems (CPS). CPS capture data of the physical world via sensors, use the Internet, and cloud computing to communicate between the connectors, and interact with the physical world utilizing mechatronic actuators (Lee 2008; Zsifkovits and Woschank 2019). This enables autonomous control systems, which can satisfy customer demands in real-time (Spath et al. 2013; Dallasega et al. 2017). CPS, as well as the Internet of Things (IoT), allow enterprises to sense deviations from the production plan as soon as they appear and identify delays in real-time (Magoutas et al. 2014; Chaopaisarn and Woschank 2019).

This chapter further investigates the postulated impact of different levels of planning periods on logistics performance indicators in combination with the application of three PPC strategies. Therefore, the initial simulation model from Woschank et al. (2020) was updated, reconfigured, and subsequentially validated in three additional simulation experiments by using a discrete event simulation study that was configured based on the data from an industrial case study in the field of electronics manufacturing.

\subsection{Problem Formulation}

Basically, in the area of PPC strategies, most Industry 4.0-related approaches are focusing on the principles of decentralization and/or aim to integrate real-time data for the ongoing improvement of the overall logistics performance in terms of promised delivery dates, work in progress, capacity utilization, and lead-times.

In a first step, the authors aim to evaluate significant differences regarding the impact of a material requirement planning (MRP), a KANBAN, or a constant work in process (CONWIP) strategy on logistics performance indicators in an make to order production system. In the second step, the authors further investigate the impact of real-time 
data usage by simulating a monthly, a two-week, and a weekly planning period, within the MRP, KANBAN, and CONWIP strategy on logistics performance indicators in an make to order production system.

Consequently, the two research questions of this chapter will be formulated as follows:

- RQ1: There is a significant difference in lead-time (LT) and work in progress (WIP) between the MRP, KANBAN, and CONWIP strategy.

- RQ2: There is a significant difference in LT and WIP between a monthly plan, a two-week plan, and a weekly plan within the MRP, KANBAN, and CONWIP strategies.

\subsection{Related Work}

By reviewing the recent literature on PPC approaches in an MTO environment, the Woschank et al. (2020) identified only a handful of relevant research studies that will be presented within the next paragraphs.

- Cadavid et al. (2020) present a systematic literature review analyzing the state of the art of Machine Learning (ML) approaches applied to PPC. According to their results, scientific literature rarely considers customer, environmental, and human-in-the-loop aspects when linking ML to PPC. Moreover, applications rarely link PPC to product and process design as well as to the logistics processes.

- Cadavid et al. (2020) suggest using IoT technologies in future research to collect data and update the ML model to adapt it to manufacturing system changes.

- Panetto et al. (2019) summarize the challenges for Cyber-Physical Production Systems (CPPS) as studied by the IFAC research community. According to their results, an infrastructure is needed that supports the adaptation of models according to the changing environment over time to support modification and (self-) adaptation.

- Similary, Bendul and Blunck (2019) present the vision of Industry 4.0 to assign tasks of production control to "smart" objects, such as 
machines, parts, and products, to reach distributed control architectures with higher flexibility, higher adaptability, and, as such, a higher logistics performance.

- According to Ivanov et al. (2018), Industry 4.0 technology enables data interchange between the product and workstations, flexible stations able to execute various technological operations, and real-time capacity utilization control. However, modern production and supply chains are challenged by increasing uncertainty and risks as well as multiple feedback cycles where control theory could contribute to gain further insights regarding the management of these challenges.

- Gräßler and Pöhler (2018) describe the change of a milling workstation by adding different sensors and computers to reach a selfcontrolling cyber-physical device in a laboratory environment. Specifically, the system is distributed and decentralized whereby, through the negotiation of resources; a common planning schedule for all orders is reached. The real-time measurement of data is used to improve assessments in the planning process, improvements of process execution as well as for the identification of consequences of disturbances. However, no quantitative improvement of logistics performance indicators compared to a conventional workstation was reported.

- Similarly, Choi et al. (2017) state that, in a smart manufacturing environment, procurement, production, logistics, service, and the product itself are connected to the network and controlled in real-time based on CPS. According to them, to establish CPS manufacturing systems, real-time information exchanges from the shop-floor level to the business level need to be enabled. They argue that data acquisition from non-equipment factors, like human operators, is much more difficult to obtain than from machines because of issues like non-standardized working environments and data protection regulations.

- Hortskemper and Hellingrath (2016) present the concept of Order Allocation Flexibility and the potential of CPS in implementing and empowering the concept leading to a further increase of flexibility in the production system. However, they argue that the concept might introduce further complexity into the PPC system and the costs for such a system might not be worthwhile for all companies. 
- According to Strandhagen et al. (2017), moving toward real-time control requires new conceptual models for planning and control. They state that real-time control is, today, mostly applied on machine and production line level, while, on the planning levels, existing concepts are based on conventional concepts like cyclic data processing and re-planning. However, according to them, Industry 4.0 technologies have the potential to enable real-time planning and control of all planning activities. They argue that real-time planning and control is easier to be applied in repetitive production environments because collecting data may be easier, enabling higher volumes and quality of production data.

- Similarly, Ruiz Zúniga et al. (2017) state that, even in more advanced Industry 4.0 manufacturing companies, real-time data gathered at the shop-floor level are mostly used for monitoring different machines and work centers (e.g., processing times, failures, waiting and blocking times) and not for optimizing PPC processes.

The systematic literature review confirms the fact that there is little knowledge regarding the cause-effect relationships between different centralized and/or decentralized PPC strategies and logistics performance indicators in a make to order environment. Moreover, in contrast to the Industry 4.0 philosophy of real-time data usage, most of the data generated in production systems are frequently not completely exploited for PPC purposes. This further undermines the importance to answer the proposed research questions.

\subsection{Research Design/Methodology}

This chapter aims to investigate and revalidate the impact of different PPC strategies and real-time data usage in production systems on logistics performance indicators by conducting simulation with data from an industrial case study. Thereby, the two research questions assume different PPC strategies and that different levels of planning periods and will have a significant effect on the logistics performance of a production system in an MTO environment. 
In this context, the authors focus on the investigation of MRP, KANBAN, and CONWIP as the most important PPC strategies in industrial enterprises (Kapeller 2018). Thereby, in the centralized MRP approach, the material is pushed to the subsequent machine after processing the order. KANBAN, as a decentralized pull system, uses a control system based on cards as a trigger for the transport of material from the outbound storage. CONWIP, as a hybrid system, pursues the goal of regulated order release procedures based on the current WIP (Kapeller 2017; Kumar et al. 2007; Gstettner 1998; Jodlbauer and Huber 2008, Dolgui and Proth 2010). Moreover, according to Unver (2013), we derived three levels of planning periods from the ISA 95 framework leading to three test groups: (1) a monthly plan, (2) a two-week plan, and (3) a weekly plan (Woschank et al. 2020). Figure 5.1 displays the basic concept of our research.

In sum the two research questions were formulated as follows:

- RQ1: There is a significant difference in lead-time (LT) and work in progress (WIP) between the MRP, KANBAN, and CONWIP approach.

- RQ2: There is a significant difference in LT and WIP between a monthly plan, a two-week plan, and a weekly plan within the MRP, KANBAN, and CONWIP strategies.

Based on the formulation of the basic research questions, the research process furthermore includes the following phases:

- Phase 1: Data collection based on the production process of an electronics manufacturer

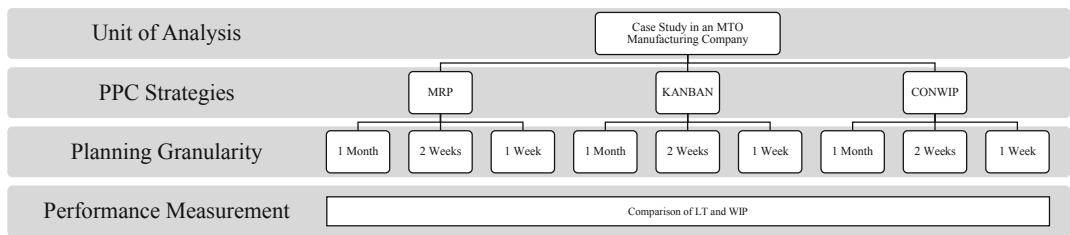

Fig. 5.1 Concept of research 
- Phase 2: Programming of the simulation model

- Phase 3: Conducting a set of simulation runs

- Phase 4: Systematic evaluation of the calculated results

According to Woschank et al. (2020), in phase 1, the data collection was based on the production process of an electronics manufacturer working as an SME in a make to order environment. Therefore, we used the secondary data from a Value Stream Mapping (VSM) as a method for the data gathering, where we focused on one specific product group. Based on the VSM, we identified the following four value-adding production processes: Step 1: production process 1 (PP1: raw printing, solver paste printing, printing check), step 2: production process 2 (PP2: picking and placing of components, soldering), step 3: production process 3 (PP3: programming and function control and step 4: production process 4 (PP4: final assembly). The supporting processes SP1 and SP2 are used for a temporary storage of material. Moreover, we recorded the following parameters for every process step: change over time, cycle time, lot size, availability, meantime to repair, LT, pieces per shift, and number of shifts. In sum, we identified the following problems: (1) The productivity of production and logistics department is quite low, (2) frequently, the customer demand cannot be satisfied, (3) high cost due to high stocklevels within the production, and (4) the planning data in the production planning system are not up to date.

Figure 5.2 displays the production process based on the initial process analysis.

Phase 2 focused on the programming of the simulation model as a tool for the systematic evaluation of research question 1 and research question 2. Thereby, we used discrete event simulation as a research method because this approach offers a high internal validity, high reliability, and the possibility to systematically isolate potential confounding variables because of the pre-defined modeling procedures (Cooper and Schindler 2014; Rabe et al. 2008; März et al. 2011; Woschank et al. 2020). Also, the transferability of the established research findings, respectively, the external validity of the simulation procedures will be ensured by using the data from the conducted VSM analysis (Bortz and Döring 2007; Woschank et al. 2020). 


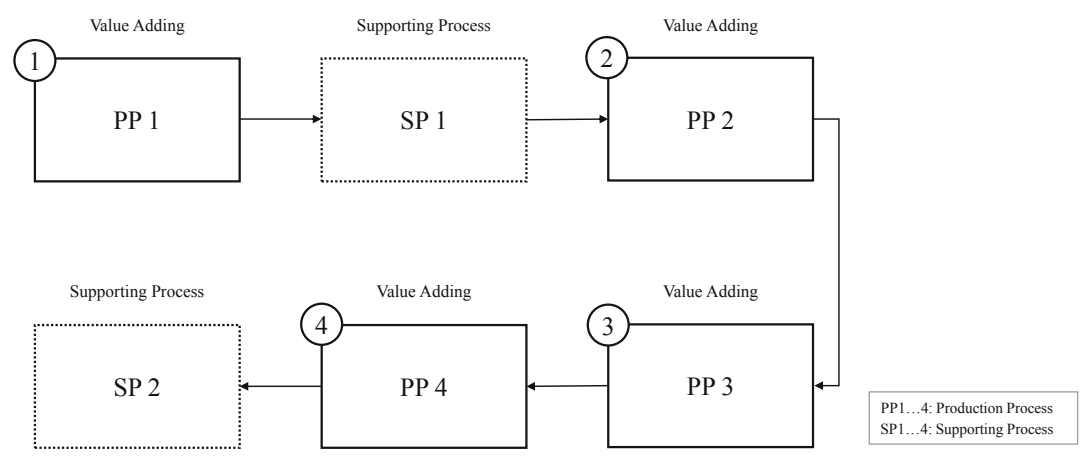

Fig. 5.2 Production process

Moreover, the research design of this paper is based on the VDI 3633 guidelines for simulation of logistics systems which consider the steps of preparation, simulation, and evaluation (März et al. 2011). In the preparation phase, we used the software Tecnomatix Plant Simulation 15.1 by Siemens PLM, which is a tool package for discrete event simulation (Woschank et al. 2020). The simulation approach is displayed in Fig. 5.3.

The final simulation approach includes three PPC strategies (MRP, KANBAN, and CONWIP), three different levels of planning periods (1 month, two weeks, and a weekly plan), and two indicators for the measurement of the logistics performance (lead-time (LT) and work in progress (WIP)). The simulation includes five machines which represent

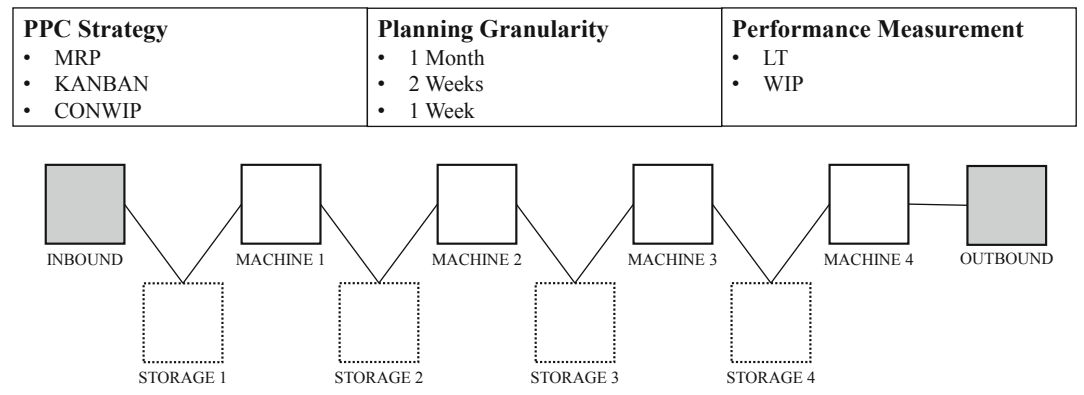

Fig. 5.3 Simulation approach 
the identified value-adding production processes (PP1-PP2), four intermediate storages in the production system as well as an inbound and an outbound warehouse.

In phase 3 , the author conducted a set of simulation runs by applying the MRP, KANBAN, and CONWIP approach to the production system. Thereby, in line with Woschank et al. (2020), the different levels of planning periods were simulated by generating three different test groups. Test group 1 is based on the usage of a monthly plan, test group 2 uses a two-week plan, and test group 3 uses a weekly plan for the PPC process. The logistics performance was operationalized by using a set of manifest indicators. In this case, we focused on the measurement of LT and the measurement of WIP in the production system.

In sum, the authors conducted three simulation experiments with nine simulation models, leading to 27,818 simulation runs within the first simulation experiment. Moreover, within a second simulation experiment, the authors furthermore computed 83,454 simulation runs, which did not show any significant difference $(\mathrm{p}<0.05)$ in comparison with the initially computed results. Finally, the authors conducted a third simulation experiment with 24,559 simulation runs leading to 49,118 performance indicators for the subsequent statistical analysis.

\subsection{Results and Discussion}

Figure 5.4 displays an overview of the conceptualized PPC strategies in the present case study.

In phase 4, the authors systematically evaluate the calculated results from the third simulation experiment to answer the following research questions:

- RQ1: There is a significant difference in lead-time (LT) and work in progress (WIP) between the MRP, KANBAN, and CONWIP strategy.

- RQ2: There is a significant difference in LT and WIP between a monthly plan, a two-week plan, and a weekly plan within the MRP, KANBAN, and CONWIP strategies. 


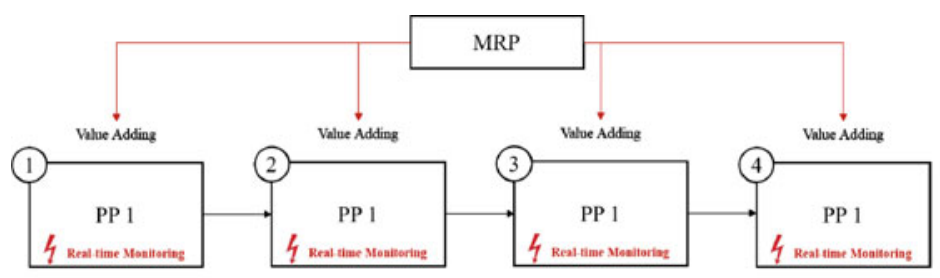

$\longrightarrow$ Mnerial Flow

Ifocratios Flow

PPC strategy 1: MRP concept coupled with real-time progress measurement

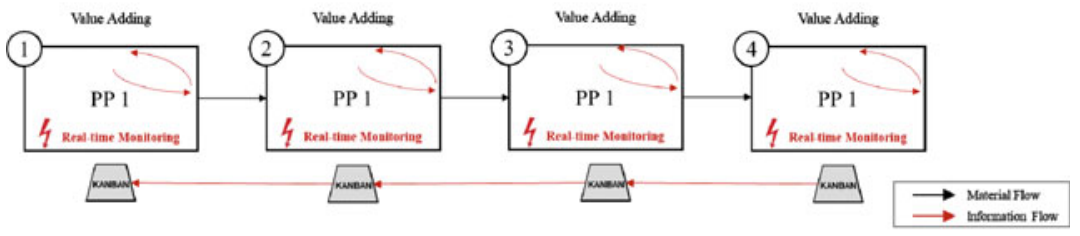

PPC strategy 2: KANBAN concept coupled with real-time progress measurement

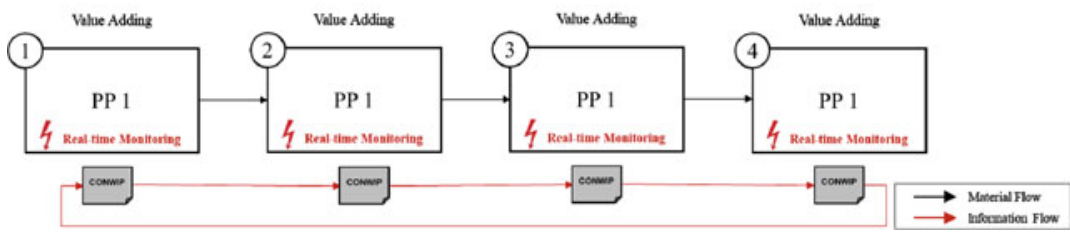

PPC strategy 3: CONWIP concept coupled with real-time progress measurement

Fig. 5.4 PPC strategies

\subsubsection{Research Question 1 (RQ1): Comparative Evaluation of PPC Strategies}

To answer research question 1, the authors conducted a comparative evaluation of the three pre-defined PPC strategies. Therefore, a one-way analysis of variance (ANOVA) was used to evaluate significant differences in the two logistics performance indicators lead-time (LT) and (WIP) between the MRP, KANBAN, and CONWIP strategies. Therefore, the authors used the software package IBM SPSS Statistics 26 for the computation of the statistical procedures. The summarized results of the conducted ANOVA analyses are displayed in Fig. 5.5 and Fig. 5.6. 
5 Investigation of the Potential to Use Real-Time Data ...

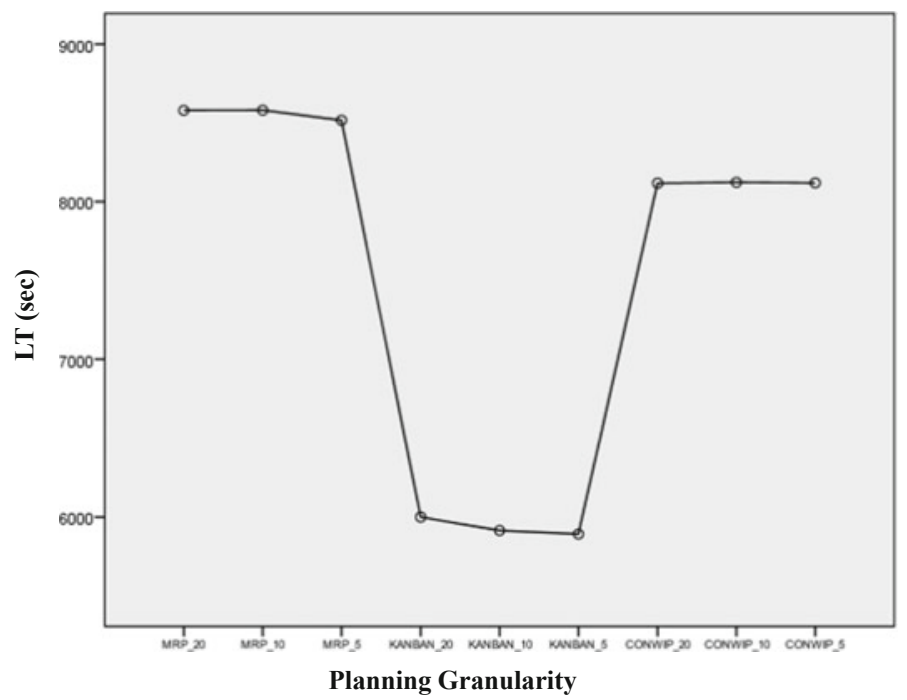

Fig. 5.5 Comparison of PPC strategies-lead-time (LT)

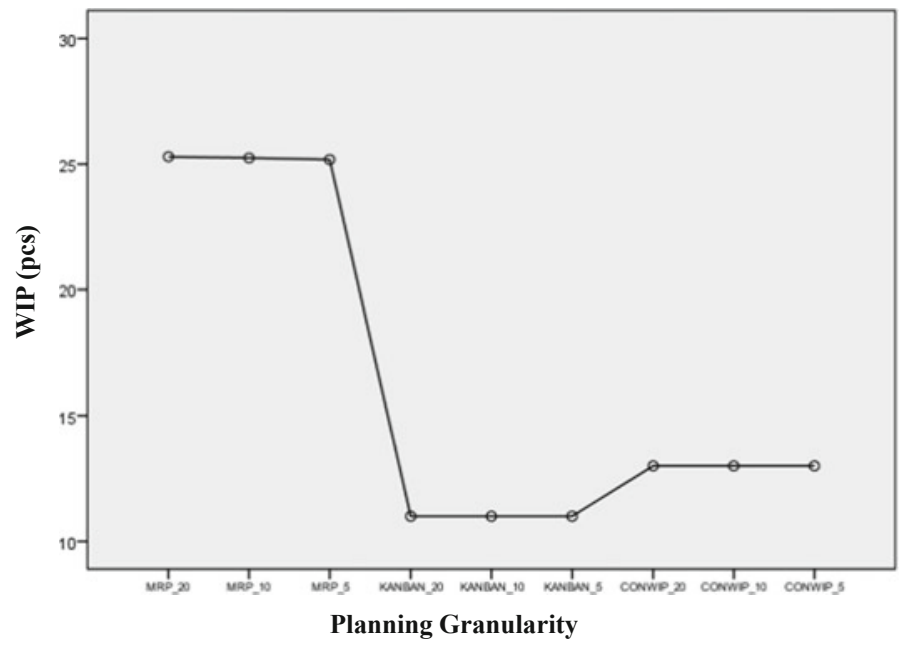

Fig. 5.6 Comparison of PPC strategies-work in progress (WIP) 
Following Fig. 5.5 and Fig. 5.6, the results of the ANOVA revealed a highly significant difference $(\mathrm{p}<0.01)$ in LT and WIP between MRP, KANBAN, and CONWIP based on a monthly planning period.

Moreover, the descriptive statistics of the computed sample are displayed in Table 5.1.

In detail, MRP, as the conventional pull-based strategy, leads to the longest LT and the highest WIP in the production system. Moreover, a T-test showed highly significant differences $(\mathrm{p}<0.01)$ in LT and WIP between the MRP and the KANBAN strategy on the level of a monthly planning period. In detail, compared to MRP, the implementation of KANBAN would lead to a reduction of $30.07 \%$ in LT and a reduction of $56.51 \%$ in WIP.

An additional T-test further revealed highly significant differences ( $\mathrm{p}$ $<0.01$ ) in LT and WIP between the MRP and the CONWIP strategy on the level of a monthly planning period. In detail, the implementation of CONWIP would lead to a reduction of $5.37 \%$ in LT and $48.60 \%$ in WIP, in comparison with the MRP approach.

\subsubsection{Research Question 2 (RQ2): Evaluation of Real-Time Data Usage within the PPC Strategies}

In the first step, the authors evaluated the effects of real-time data usage within the MRP strategies by using three test groups for the pre-defined levels of planning periods. Therefore, we used a one-way analysis of variance (ANOVA) to test significant differences in lead-time (LT) and work in progress (WIP) between a monthly, a two-week, and a weekly planning period. The computed ANOVA results are displayed in Fig. 5.7 and Fig. 5.8 .

Within the MRP strategies, the computed ANOVA revealed highly significant differences $(\mathrm{p}<0.01)$ in lead-time (LT) and work in progress (WIP) between a monthly, a two-week, and a weekly planning period. The detailed statistical analysis revealed, that, within the MRP strategies, a higher level of planning will lead to better LT and a lower WIP, but only with a relatively low effect. In detail, a reduction in planning from 


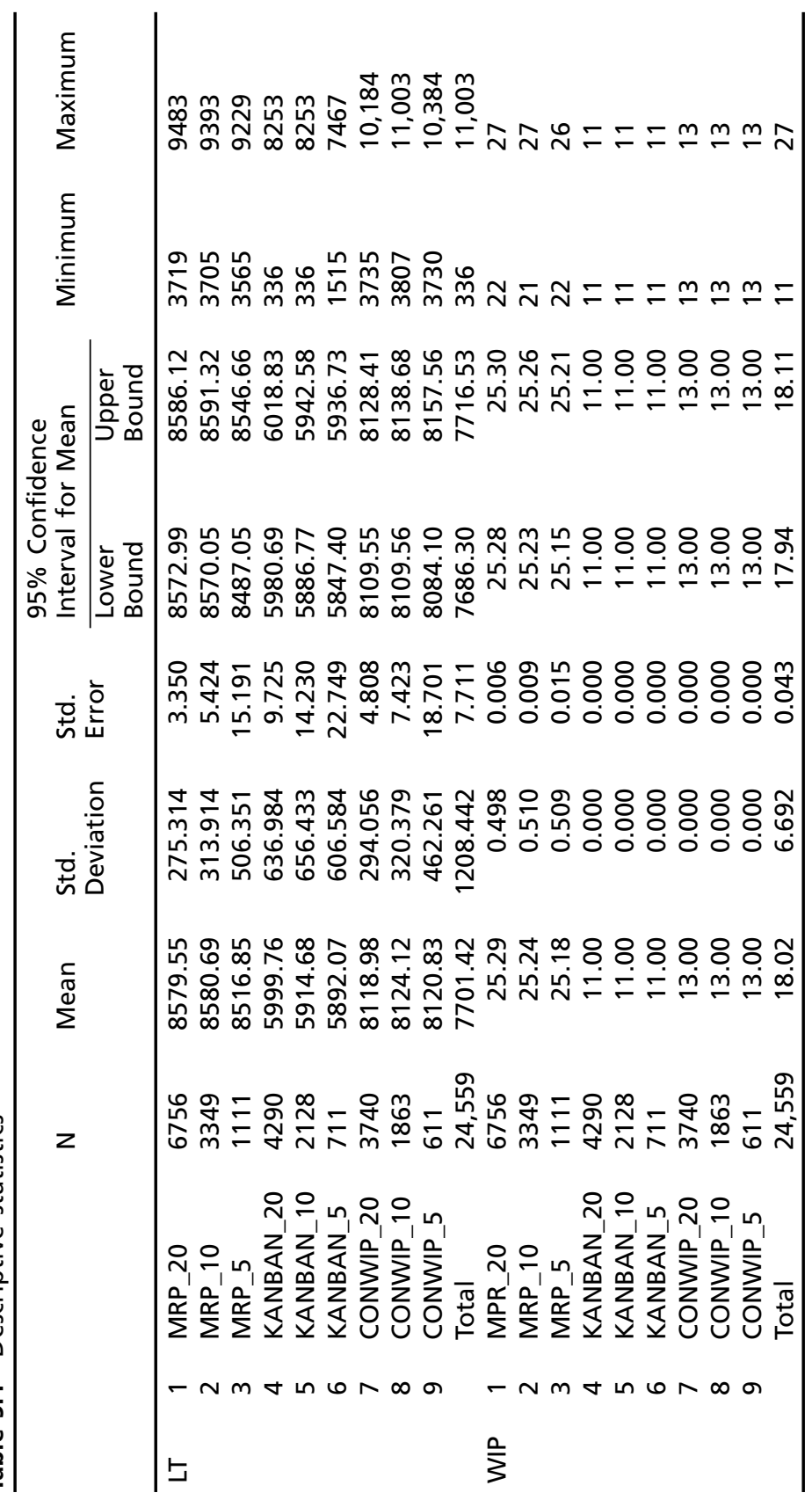


M. Woschank et al.

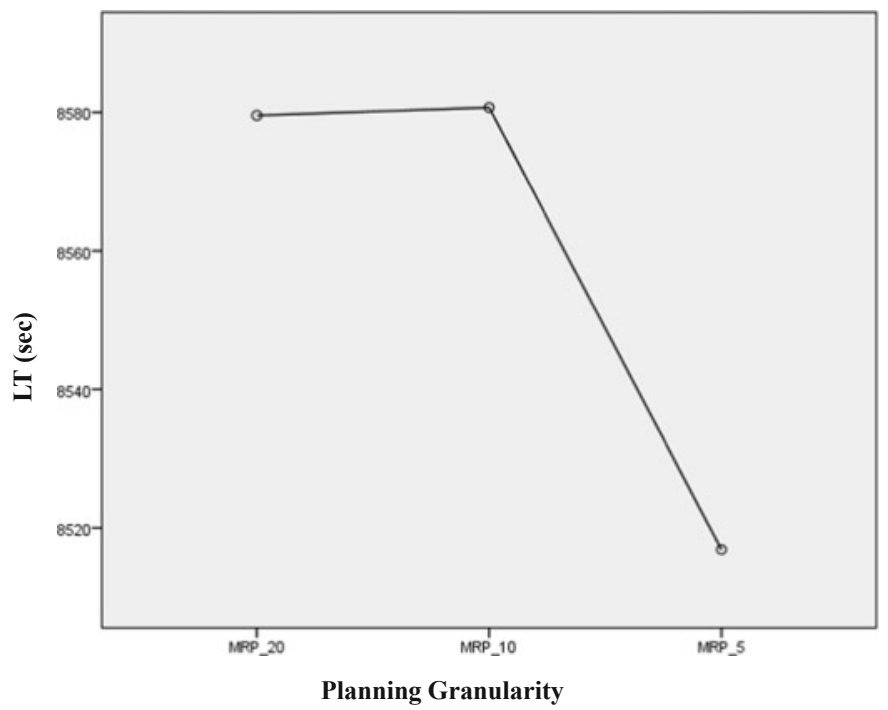

Fig. 5.7 Real-time data usage within the MRP strategy-lead-time (LT)

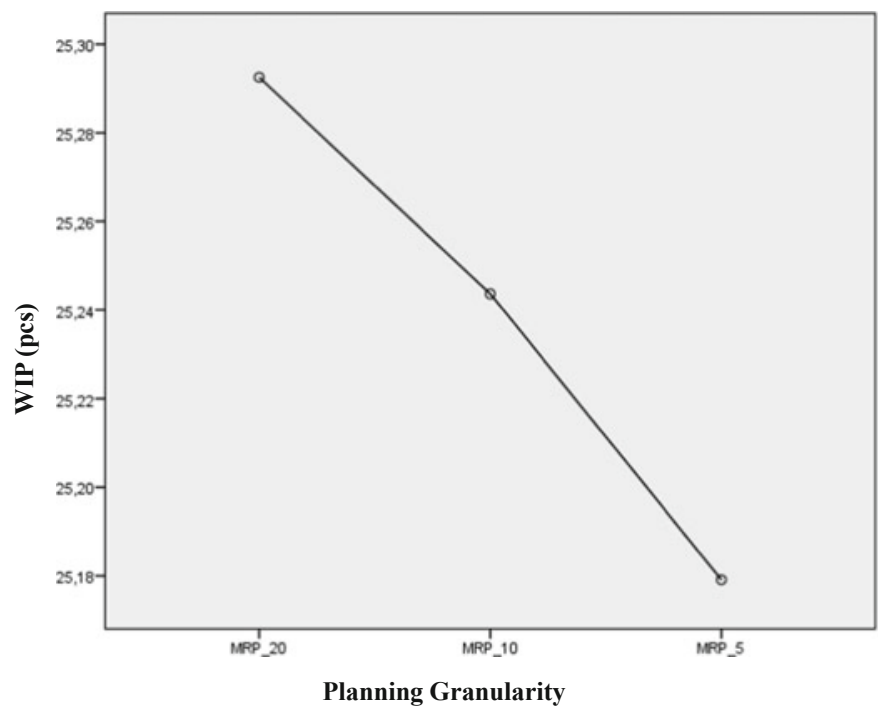

Fig. 5.8 Real-time data usage within the MRP strategy-work in progress (WIP) 
a monthly plan to a weekly plan would result in a reduction of $0.73 \%$ in LT and $0.45 \%$ in WIP.

In the second step, the authors evaluated the effects of real-time data usage within the KANBAN strategies by using a one-way analysis of variance (ANOVA) to test significant differences in lead-time (LT) and work in progress (WIP) between a monthly, a two-week, and a weekly planning period. The computed ANOVA results are displayed in Fig. 5.9.

Within the KANBAN strategies, the computed ANOVA revealed highly significant differences $(\mathrm{p}<0.01)$ in lead-time (LT), but no significant differences $(\mathrm{p}>0.05)$ work in progress (WIP) between a monthly, a two week, and a weekly planning period. Thereby, the detailed statistical analysis revealed, that, within the KANBAN strategies, a higher level of planning will lead to a reduction of $1.79 \%$ in LT.

In the third step, the authors evaluated the effects of real-time data usage within the CONWIP strategies by using three test groups for the pre-defined levels of planning periods. Therefore, we used a one-way analysis of variance (ANOVA) to test significant differences in lead-time

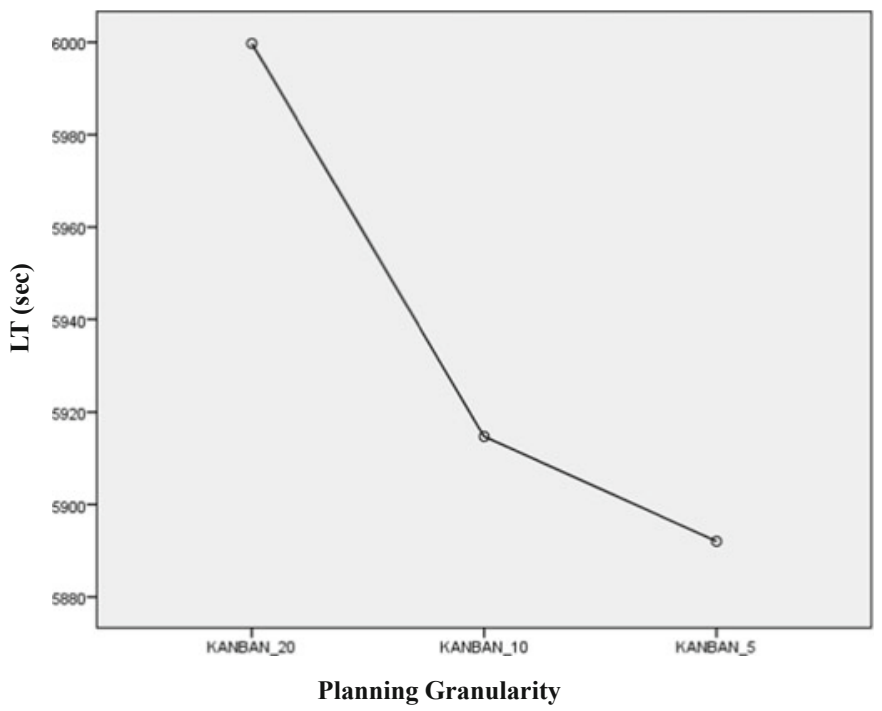

Fig. 5.9 Real-time data usage within the KANBAN strategy-lead-time (LT) 
(LT) and work in progress (WIP) between a monthly, a two-week, and a weekly planning period. However, within the CONWIP strategies, the computed ANOVA results showed no significant differences $(\mathrm{p}<0.010)$ in LT and no significant differences in WIP between a monthly plan, a two-week plan, and a weekly plan. Therefore, the authors conclude that different planning periods have no significant effect on the LT and WIP within the CONWIP approach.

\subsection{Conclusions and Outlook}

In this chapter, the authors have updated and reconfigured the simulation model by Woschank et al. (2020) to investigate and subsequently validate and the impact of different PPC strategies and different levels of planning periods on logistics performance indicators by using a discrete event simulation based on an industrial case study.

Research question 1 aimed to investigate significant differences in lead-time (LT) and work in progress (WIP) between the MRP, KANBAN, and CONWIP strategy. Thereby, the results of the statistical analysis confirmed significant differences between MRP, KANBAN, and CONWIP in WIP and LT (Fig. 5.5). Moreover, the KANBAN approach performed best in terms of WIP and LIT. In detail, the application of the KANBAN strategy would lead to a reduction of $30.07 \%$ in LT and a reduction of $56.51 \%$ in WIP, while the implementation of CONWIP would lead to a reduction of $5.37 \%$ in LT and $48.60 \%$ in WIP, in comparison with the traditional MRP strategy.

Research question 2 was formulated to investigate significant differences in LT and WIP between a monthly plan, a two-week plan, and a weekly plan within the MRP, KANBAN, and CONWIP strategies. Hereby, the statistical analysis showed significant differences in LT and WIP within the MRP strategy and significant differences in LT within the KANBAN strategy according to the different levels of planning periods (Fig. 5.7). In this case, this could be explained because the usage of real-time data could have a positive impact on the adaptation of the system to changes, thus making the system more responsive. Within 
the CONWIP strategy, no significant differences in LT and WIP were indicated between the different levels of planning periods.

In general, this chapter contributes to a better understanding of PPC strategies and the usage of real-time data in production systems. The updated and reconfigured simulation model from Woschank et al. (2020) further increases the transferability and, therefore, the external validity of the computed statistical results and the established research findings. Future research should focus on the further development of the proposed model by transferring it to other industrial branches, by incorporating additional PPC strategies, or by using a different set of products and/or machines within the simulation model.

Acknowledgements This research is part of the project "SME 4.0 - Industry 4.0 for SMEs”, which has received funding from the European Union's Horizon 2020 research and innovation program under the Marie Skłodowska-Curie grant agreement No. 734713.

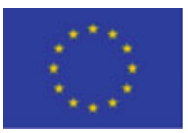

\section{References}

Arica, E., and D.J. Powell. 2014. A framework for ICT-enabled real-time production planning and control. Advances in Manufacturing 2 (2): 158164. https://doi.org/10.1007/s40436-014-0070-5.

Bednar, S., and V. Modrak. 2014. Mass customization and its impact on assembly process' complexity. International Journal for Quality Research 8(3): 417-430. https://www.ijqr.net/journal/v8-n3/10.pdf.

Bendul, J.C., and H. Blunck. 2019. The design space of production planning and control for industry 4.0. Computers in Industry 105: 260-272. https:// doi.org/10.1016/j.compind.2018.10.010.

Bortz, J., and N. Döring. 2007. Forschungsmethoden und Evaluation. Für Human- und Sozialwissenschaftler, 4th ed. Berlin et al.: Springer. 
Cadavid, J.P.U., S. Lamouri, B. Grabot, R. Pellerin, and A. Fortin. 2020. Machine learning applied in production planning and control: A state-ofthe-art in the era of industry 4.0. Journal of Intelligent Manufacturing 31: 1531-1558. https://doi.org/10.1007/s10845-019-01531-7.

Chaopaisarn, P., and M. Woschank. 2019. Requirement analysis for SMART supply chain management for SMEs. In Proceedings of the International Conference on Industrial Engineering and Operations Management, 37153725. Bangkok, Thailand.

Choi, S., G. Kang, C. Jun, J.Y. Lee, and S. Han. 2017. Cyber-physical systems: A case study of development for manufacturing industry. International Journal of Computer Applications in Technology 55 (4): 289-297. https://doi.org/10.1504/IJCAT.2017.086018.

Cooper, D.R., and P.S. Schindler. 2014. Business research methods, 12th ed. New York: McGraw-Hill.

Dallasega, P., R.A. Rojas, E. Rauch, and D.T. Matt. 2017. Simulation based validation of supply chain effects through ICT enabled real-time-capability in ETO production planning. Procedia Manufacturing 11: 846-853. https:// doi.org/10.1016/j.promfg.2017.07.187.

Dallasega, P., R.A. Rojas, G. Bruno, E. Rauch, and E. 2019. An agile scheduling and control approach in ETO construction supply chains. Computers in Industry 112: 103-122. https://doi.org/10.1016/j.compind. 2019.08.003.

Dallasega, P., M. Woschank, S. Ramingwong, K. Tippayawong, and N. Chonsawat. 2019b. Field study to identify requirements for smart logistics of European, US and Asian SMEs. In Proceedings of the International Conference on Industrial Engineering and Operations Management, 844-855. Bangkok, Thailand.

Dallasega, P., M. Woschank, H. Zsifkovits, K.Y. Tippayawong, and C.A. Brown. 2020. Requirement analysis for the design of smart logistics in SMEs. In Matt, D.T., V. Modrák, and H. Zsifkovits (eds.). Industry 4.0 for SMEs, 147-162. Cham: Springer.

Dolgui, A., and J.P. Proth. 2010. Supply chain engineering. Useful methods and techniques. London et al.: Spinger.

Gräßer, I., and A. Pöhler. 2018. Intelligent devices in a decentralized production system concept. Procedia CIRP 67: 116-121. https://doi.org/10.1016/ j.procir.2017.12.186.

Gstettner, S. 1998. Leistungsanalyse von Produktionssystemen. Heidelberg: Physica. 
Horstkemper, D., and B. Hellingrath. 2016. Employing order allocation flexibility in cyber-physical production systems. Procedia CIRP 57: 345-350. https://doi.org/10.1016/j.procir.2016.11.060.

Ivanov, D., S. Sethi, A. Dolgui, and B. Sokolov. 2018. A survey on control theory applications to operational systems, supply chain management, and Industry 4.0. Annual Reviews in Control 46: 134-147. https://doi.org/10. 1016/j.arcontrol.2018.10.014.

Jodlbauer, J., and A. Huber. 2008. Service level performance of MRP, Kanban, CONWIP and DBR due to parameter stability and environmental robustness. International Journal of Production Research 46 (8): 2179-2195. https:// doi.org/10.1080/00207540600609297.

Kapeller, J.A. 2017. Explorative Potentialevaluierung der Kombination von Fertigungssteuerungs-strategien. Ein simulationsbasierter Ansatz zur Evaluierung von Produktions- und Fertigungsverfahren im Bereich der Linienfertigung. In Zsifkovits, H., and S. Altendorfer-Kaiser (eds.). Logistisches Produktionsmanagement, 4. Wissenschaftlicher Industrielogistik-Dialog in Leoben (WiLD), 71-82. Berlin: epubli.

Kapeller, J.A. 2018. EoPaMS. Systematische Potentialevaluierung der sequentiellen Kombination von Fertigungssteuerungsstrategien für den Bereich der Linienfertigung. Ein simulationsbasierter Ansatz. Dissertation. Montanuniversitaet Leoben: Leoben.

Kumar, C.S., and R. Panneerselvam. 2007. Literature review of JIT-KANBAN system. the International Journal of Advanced Manufacturing Technology 32 (3): 393-408. https://doi.org/10.1007/s00170-005-0340-2.

Lee, E.A. 2008. Cyber physical systems: Design challenges. In Proceedings of the 11th IEEE International Symposium on Object and Component-Oriented Real-Time Distributed Computing, 363-369.

Magoutas, N., N. Stojanovic, A. Bousdekis, D. Apostolou, G. Mentzas, and L. Stojanovic. 2014. Anticipation-driven architecture for proactive enterprise decision making. Proceedings of the CAiSE 2014: 121-128.

März L., W. Krug, O. Rose, and G. Weigert. 2011. Simulation und Optimierung in Produktion und Logistik. Praxisorientierter Leitfaden mit Fallbeispielen. Berlin: Springer.

Matt, D.T., and E. Rauch. 2016. Designing assembly lines for mass customization production systems. In Modrak, V. (ed.). Mass customized manufacturing. Theoretical concepts and practical approaches, 15-36. Boca Raton: CRC Press.

Panetto, H., B. Iung, D. Ivanov, G. Weichhart, X. Wang, and X. 2019. Challenges for the cyber-physical manufacturing enterprises of the future. Annual 
Reviews in Control 47: 200-213. https://doi.org/10.1016/j.arcontrol.2019. 02.002 .

Rabe, M., S. Spieckermann, and S. Wenzel. 2008. Verifikation und Validierung für die Simulation in Produktion und Logistik. Vorgehensmodelle und Techniken. Berlin, Heidelberg: Springer.

Ruiz Zúñiga, E., A. Syberfeldt, and M. Urenda Moris. 2017, The Internet of Things, Factory of Things and Industry 4.0 in Manufacturing: Current and Future Implementations. In Proceedings of the 15th International Conference on Manufacturing Research, 221-226. Greenwich, United Kingdom. https:// doi.org/10.3233/978-1-61499-792-4-221.

Spath, D., S. Gerlach, M. Hämmerle, S. Schlund, and T. Strolin. 2013. Cyberphysical system for self-organised and flexible labour utilization. In 22nd International Conference on Production Research, 1-6.

Strandhagen, J.W., E. Alfnes, J.O. Strandhagen, and L.R. Vallandingham. 2017. The fit of Industry 4.0 applications in manufacturing logistics: A multiple case study. Advances in Manufacturing 5: 344-358. https://doi.org/ 10.1007/s40436-017-0200-y.

Unver, H.O. 2013. An ISA-95-based manufacturing intelligence system in support of lean initiatives. The International Journal of Advanced Manufacturing Technology 65 (5): 853-866. https://doi.org/10.1007/s00170-0124223-z.

Woschank, M., P. Dallasega, and J.A. Kapeller. 2020. The impact of planning granularity on production planning and control strategies in MTO: A discrete event simulation study. Procedia Manufacturing. In press 1-6.

Zsifkovits, H.E., and M. Woschank. 2019. Smart Logistics - Technologiekonzepte und Potentiale. BHM Berg-Und Hüttenmännische Monatshefte 164 (1): 42-45. https://doi.org/10.1007/s00501-018-0806-9. 
Open Access This chapter is licensed under the terms of the Creative Commons Attribution 4.0 International License (http://creativecommons.org/ licenses/by/4.0/), which permits use, sharing, adaptation, distribution and reproduction in any medium or format, as long as you give appropriate credit to the original author(s) and the source, provide a link to the Creative Commons license and indicate if changes were made.

The images or other third party material in this chapter are included in the chapter's Creative Commons license, unless indicated otherwise in a credit line to the material. If material is not included in the chapter's Creative Commons license and your intended use is not permitted by statutory regulation or exceeds the permitted use, you will need to obtain permission directly from the copyright holder.

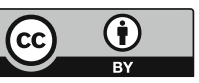

